\title{
Comparative Analysis of the Movie "Wandering the edge" and the Original from Practical Significance
}

\author{
Yuan Yang ${ }^{1, a}$ and Dongmei Yu ${ }^{1, b}$ \\ ${ }^{1}$ Beihua University Foreign Languages' College, Jilin ,China \\ a Alice 5566@163.com, b421432252@qq.com
}

Keywords: Wandering the edge; Juvenile crime; Revenge; Law; Education

\begin{abstract}
The film "wandering blade" was adapted from the Japanese novelist KeigoHigashino's novel of the same name, and was moved to the screen in Japan and South Korea until 2014. Describes the father were brutally slaughtered daughter of juvenile killer story of revenge. In the film, some problems such as law, family and education faced by modern society were put forward. These problems not only exist in neighboring countries, Japan and South Korea, but also the common problems of countries in the new era. It is worth us to think deeply and make joint efforts to solve them.
\end{abstract}

Acknowledgement: This research was financially supported by the 2016Reasearch Project of Educational Science in Jilin(GH16080).

\section{电影《彷彺之刃》与原著的对比及其现实意义分析 杨圆，于冬梅 \\ 北华大学外语学院，吉林 吉林 132013}

摘要: 电影《彷徨之刃》改编自日本作家东野圭吾的同名小说，截止到 2014 年分别在日本和韩国被搬上大荧幕。主要 讲述了父亲为被残忍虐杀的女儿对未成年人凶手进行复仇的故事。在电影中提出了现代社会面临的法律、家庭、教育等一些 列问题。而这些问题不仅仅存在于邻国日本和韩国，也是新时代下各国的共通问题，值得我们去深思及共同努力解决。

关键词: 彷徨之刃；未成年犯罪；复仇；法律；教育

1 前言

《彷得之刃》是根据日本著名作家东野圭吾的同名小说改编而成的电影，目前共有日本版和韩国版两 个版本上映。《彷徨之刃》最初是在日本杂志《周刊朝日》上连载, 后整理成单行本出版。主要讲述了与 女儿相依为命的父亲长峰重树，在女儿被两个未成年人残忍虐杀后，进行复仇而成为被通缉的杀人犯的故 事。一经出版便销售量惊人的同时，《彷得之刃》也成为东野圭吾作品中较具争议的一篇，在日本网站上 一直处在东野圭吾作品推荐的前十位。加之两度被进行改编，搬上大荧幕，在读者群中也引发了对电影和 原著的比较及评议的热潮。本文拟通过电影化的《彷得之刃》的两个版本同原著的对比，来分析电影欲传 达给人们的主题, 借此阐述《彷得之刃》电影化的现实意义。

\section{2 日本版《彷得之刃》与原著的对比}

日本版《彷得之刃》由益子昌一执导，于 2009 年 10 月 10 日上映，并在蒙特利尔国际电影节展演。 饰演男主人公的日本演员寺尾聪还凭借在此片的出色诠释, 获得了第 19 回日本电影批评家大奖的最佳男 主角奖。而寺尾聪的获奖也可以说是实至名归，因为相较于原著中对不同出场人物的描写，日本版《彷得 之刃》的情节展开主要都是由男主人公串连起来的。而与原著最显著的不同有以下几点: 


\section{1 人物设定}

与原著不同的是, 在日本版《彷得之刃》中, 对出场人物进行了部分重新的设定。主要的变化有: 首 先, 男主人公虽然名字未做修改, 但是却省略了原著中对其喜爱射击这一方面的介绍。从整个电影的设置 来看, 这一改动为后来男主人公从民宿老板那里获得猎枪而并非自己携带枪支进行了铺垫。使得男主人公 最后被警察射杀时的一幕显得更加悲情。其次, 改动较大的是告密者中井诚, 在原著里, 中井诚的告密是 有目的性的, 即通过男主人公之手杀死凶手菅野快儿和伴崎敦也, 让自己完全脱险。在长峰重树因看到女 儿被凌虐的录像带而无法克制地刺了伴崎敦也一刀后, 实际上没有把伴崎敦也杀死。中井诚为进行确认潜 入屋子的时候, 伴崎敦也明显是活着的, 但是中井要他死, 所以最后才会说出: “你怎么还没有死? ” 这 样的话。而这种肆无忌惮发泄出来的残忍的恶意在电影中并未表现。最后, 在电影中值得注意的人物改动 还有警察织部孝史, 在原著中织布孝史始终处于矛盾的状态, 作为一名年轻的警察, 要听从于上级的命令, 但是对于现实生活中的犯罪还没有深刻的领悟。因此, 他充满了对男主人公遭遇的同情。不过, 在电影中 显示出来的是他虽然迷茫, 但是却明显站在了长峰重树的一边, 这一改动是符合电影情节发展的需要的。

\section{2 情节设定}

对于原著的改编, 完全是为了电影的情节设定和发展服务的。从这一方面看, 主要的变化有: 首先是 凶手犯罪的手法, 在原著中详细地说明了凶犯犯罪的手法, 即蹲点, 找猎物, 最后绑架, 并且为了省去力 气直接用了氯仿这样危险的药品。虽然明知如果用量掌握不好, 就会害死被绑架者, 但是他们并不关心这 些, 只关心快点有猎物出现。凶犯从从本性上欺凌弱小, 随意糟蹋毫无反抗能力的女性。其次, 男主人公 到长野县后入住的民宿的父女的情节设定也引人深思。同原著里描写的一样，同样是父亲和单亲女儿相依 为命。并且电影中民宿老板的女儿佳子也向警察举报了男主人公的行踪。但是最后民宿老板为男主人公挡 住警察, 帮助其逃脱并将车子和留有两发子弹的猎枪留给了长峰重树。同样身为父亲, 民宿老板深刻地体 会到男主人公的心境, 因此向警察织部孝史请求, 能否做些什么帮助一下男主人公。这一情节的设定, 让 观众更加能够与男主人公之间形成共感，使得一直独自行动的男主人公身上多了一丝丝的关怀。

\section{3 结局部分的处理}

整部电影改动最大的, 可以说是长峰重树的复仇目的。最后一幕中他与织部孝史的通话, 可以看出他 完全不想杀人, 他的目的只是让菅野快儿感受到死亡的恐惧, 是抱着让菅野快儿受教育, 故意摆出要对他 开枪的姿势。从这一点来看, 电影的改动并不是很成功。首先, 从为女儿复仇的愤怒一下子转变成像完全 忘记女儿的惨死一样, 为凶犯的未来考虑。这样的变化未免过于伪善, 将本可以使电影主题升华的内容无 法显现。不得不说, 日本版的改编在结局的处理上, 太过保守, 未能展现出东野圭吾原著作品中拷问人心 的气势。但是值得一提的是, 整个影片的情节发展十分平缓, 因此给人一种压抑感, 这种气氛的营造让人 久久不能释怀, 是本片的亮点所在。

\section{3 韩国版《彷得之刃》与原著的对比}

韩国版《彷得之刃》由韩国导演李正浩执导，于 2014 年 4 月 10 日在韩国上映。上映首日就获得全国 观影人数第二名的成绩。对于原著的改编, 导演李正浩十分慎重, 亲自改编, 在开机前已经修改了近 50 余稿。相较于原著, 韩国版的首要改动就是将人物和事件发生背景本土化。其中主要的特点有: 


\section{1 人物设定}

首先, 男主人公设定为在纺织厂工作的车间组长, 名为李胜贤。由于每天都加班到很晚, 同原本失去 母亲的女儿关系紧张。在得知女儿被残忍虐杀后充满了悔恨和愤怒, 一心要为女儿复仇。其次, 同日本版 不同的是, 年轻刑警朴玄洙（原著中的织部孝史）基本符合原著的人物性格。不同是的加重了其上司刑警 张亿观 (原著中老刑警真野) 的戏份。对这名老练的刑警的人物设定进行了改编。刑警张亿观因为对高中 生暴力案件的侦查, 致使仍是未成年人罪犯精神出现问题, 而无法向家长和社会舆论交代。也正是这样的 经历让他开始反思, 也因此对于男主人公的遭遇给予了深切的同情。最后, 在韩国版《彷得之刃》中, 原 著中的民宿父女并未出场。但是加重了犯罪人赵斗植（原著中的菅野快儿）的戏份, 这也为情节的发展买 下了伏笔。

\section{2 情节设定}

韩国版《彷得之刃》的基本情节是忠实于原著的。但是在部分情节的处理和改编上又具有韩国电影的 特色。首先, 受害人并非被抛尸在河岸边, 而是像破烂的玩偶般被抛尸在废弃小区的浴池里。其次, 对于 犯罪人的情节设定, 也让观众感受到了未成年犯罪对于人命的无视。在男主人公根据匿名短信找到凶犯金 哲勇（原著中伴崎敦也）的住处，在杀死金哲勇时，凶犯唯一想到被袭击的理由竟是以为被偷的 ipad 的 主人来寻仇。同原著相比, 这两个情节设定让人更加不寒而栗。除此之外, 在男主人公追杀凶犯赵斗植时, 无意中发现了与赵斗植相关联, 以补习班为名义的高中生卖淫据点, 从而引出了另一个社会问题, 即离家 出走的女高中生们被蒙骗进行卖淫的社会现象。这一情节让电影更具有社会性和话题性。最后, 值得关注 的情节还有被杀死的凶犯金哲勇的家长否认其犯下的残忍罪行, 认为 17 岁的儿子不会作出那种事。而是 以被害人的身份要求警察将男主人公抓获。此时镜头切换到另一场景, 同样受到这两名凶犯迫害的未成年 女孩因为承受不了心理压力自杀, 其母在警察局扬言要杀死施暴的孩子, 并恳请警察抓捕罪犯。以上的情 节设定，是不同于原著的，但又在主题上同原著相契合。法律保护的到底是谁？與论的焦点应该在哪里? 一些列的问题都值得人们深思。

\section{3 电影结局部分的处理}

韩国版《彷得之刃》的结局部分的处理也是让人倍感悲凉的。男主人公同样并未在猎枪里安放子弹, 也是早已选择要离开这个世界。但是同原著以及日本版不同的是, 在韩国版中曾经有过这样一个情节。男 主人公在追杀凶犯赵斗植的过程中曾经在大巴车里同素未谋面的凶犯相遇, 并且凶犯还叮嘱其要注意腿伤。 也许部分观众会认为这是男主人公最后没有枪杀赵斗植的原因之一。但是, 恰恰相反, 男主人公从未过多 地考虑过这些, 他所希望的就是不要和这些畜生般的人生活在同一个世界。到死的那一刻他也没有原谅凶 犯。与日本版最后的宽容相比, 韩国版更加贴近人性以及原著作者的本意。

韩国版《彷得之刃》与原著的表现手法有些许不同, 更偏向于隐射社会上存在的合情不合法行为的矛 盾。但电影依旧以表现原著的情感为主要目的, 尽量在主题上贴近原著。可以说没有太遵循原著, 也是其 不小的突破。

\section{4 《彷得之刃》电影化的现实意义分析}

小说《彷得之刃》虽然并不是作为推理小说而受到推崇, 但是其内涵的社会问题却一直拷问人心, 使 人无法释怀。因此, 才会有被两度电影化的情况出现。而两度电影化的《彷得之刃》又一次将一系列的问 
题展现在更多观众以及不同国家的观众面前, 更加推动了人们对现代社会问题的思考。其电影化现实意义 还在于:

\section{1 法律层面}

又一次对未成年犯罪的量刑和对未成年罪犯的保护提出了疑问。在电影《彷得之刃》中，未成年罪犯 深知因为自己未成年，可以逃脱严重的法律制裁，从而藿视人命。在将受害人迫害致死后仍旧没有任何悔 改之心。法律保护着这样的人, 正义该如何彰显? 不得不说是值得深思的法律层面的问题。而日本版《彷 得之刃》中, 民宿老板的女儿佳子的话也发人深省。佳子对男主人公提出疑问： “以暴制暴, 能解决根本 问题吗? ”, 而男主人公只有沉默以对, 他心里自然是清楚的, 答案是不能。但是如何用法律来解释和解 决这一切, 也是仍待解决的严峻问题。

\section{2 家庭层面}

在韩国版《彷得之刃》中, 能更多地看到家庭的影响。男主人公本应该在事发当晚撑着雨伞去地铁站 接女儿回家, 但因加班而无暇顾及, 导致女儿被绑走最后被虐杀。对此, 男主人公一直是充满了悔恨。另 一方面，罪犯金哲勇的家长在得知自己的孩子犯下的罪行后，矢口否认，一味地让警察抓获凶手，可见其 平时的家庭教育情况。此外, 补习班内离家出走的卖淫女高中生们也远离自己的家庭。这些都引发出电影 要传达给人们的一个主题, 即社会问题的背后往往都存在着家庭问题。因此，良好的家庭环境也是杜绝犯 罪的重要因素。

\section{3 教育层面}

中国的高等教育发展到今天，也一直很重视参考日韩两国的教育体制及教育方法。但是可以看出，在 邻国, 教育问题仍旧也是层出不穷的。例如, 在日本版中告密者因害怕受到欺负, 而协助犯罪。韩国版中 的告密者在被得知告密后, 被同学们视为叛徒。本该是让学生们追求梦想, 健康成长的学校, 反而出现了 欺凌同学现象, 并且滋长犯罪。这些都反映出学校教育出现了问题, 如何让学生身心健康的成长, 使之成 为社会的正能量。这也是电影传达给人们需要思考的主题之一。

虽然经日本和韩国电影化的《彷得之刃》均与原著有着差别，但是在提出社会问题及引人深省的现实 意义上均有其各自的视角和特点。

\section{5 致谢}

感谢吉林省教育科学 “十三五” 规划课题, 本论文为吉林省教育科学规划课题《网络教学中的日语精 读的课程设计》（课题批准号为 GH16080）的成果之一。

\section{参考文献:}

［1］［日]东野圭吾刘珮瑄译. 彷得之刃 [M]，南海出版公司，2015， p77-90.

[2] 范忠武. 东野圭吾推理小说的电影改编 [J]，电影文学，2015（21）, p15.

[3] 周婷. 电影作品的民族性价值 $[J]$ ，电影文学，2015（15），p30.

[4] 张景一，论东野圭吾作品中的新社会派特性 $[J]$ ，当代文坛，2014（04），p17.

\section{References}

[1] (Japanese) Higashino Keigo, P.X.Liu(Translation): The Hovering Blade[M], Nai Hai Publishing Company, 2015, p77-90.

[2] Z.W.Fan: The Film Adaptation of Keigo Higashino's whodunit[J], Movie Literature, 2015(21),p15.(In Chinese)

[3] T.Zhou: The National Value of the Film Works[J], Movie Literature, 2015(15), p30.(In Chinese) 
[4] J.Y.Zhang: On the Characteristics of the New Sociological School in Keigo Higashino's Works[J], Modern Literary Magazine, 2014(04),p17.(In Chinese) 